\title{
Is Gastroesophageal Reflux Disease Really a Risk Factor for Acute Myocardial Infarction?
}

\author{
Su Young Kim \\ Division of Gastroenterology, Department of Internal Medicine, Yonsei University Wonju College of Medicine, Wonju, Gangwon-do, Korea
}

Article: The risk of acute myocardial infarction in patients with gastroesophageal reflux disease

Eisa M, Sandhu A, Prakash R, Ganocy SJ, Fass R

(J Neurogastroenterol Motil 2020;26:471-476)

Acute myocardial infarction (AMI) is an often-fatal disease. Well-known risk factors of AMI include diabetes mellitus, hypertension, hypercholesterolemia, smoking, alcohol consumption, and obesity. ${ }^{1}$ Gastroesophageal reflux disease (GERD) is a common gastrointestinal disorder, and is associated with esophageal acid exposure. Over the last several decades, studies have shown that GERD exacerbates myocardial ischemia and reduces coronary blood flow, ${ }^{2,3}$ but no clear conclusions have been made on the association between GERD and AMI in actual practice.

Johansson et $\mathrm{al}^{4}$ showed that GERD is not an independent predictor of myocardial infarction (odds ratio [OR], 1.1; 95\% confidence intervals $[\mathrm{CI}], 0.80-1.60)$. In contrast, according to a study published in Taiwan, GERD is independently associated with increased risk of developing AMI (hazard ratio $[\mathrm{HR}]=1.48$; 95\% CI, 1.31-1.66; $P<0.001){ }^{5}$. These results are similar to those of this present article "The risk of acute myocardial infarction in patients with gastroesophageal reflux disease"; ${ }^{6}$ in the present study, the OR of developing AMI in the GERD population was 1.1 (95\% CI, 1.08-1.13; $P<0.001$ ). One important thing this study has in common with previous clinical studies is that they are all nationwide population studies based on big data research. Due to the nature of AMI (low incidence and high fatality), researchers are fairly limited in their design of clinical trials; one particularly irksome factor is that the available variables are quite limited. AMI is a disease caused by a combination of various other factors in addition to the risk factors known to date. However, the variables actually used in previous studies (including the present study) are sex, age, simple past history, and smoking. Since there is no assessment of the subject's other risk factors (medication being used, arrhythmia, physical activity, family history, stress, etc), interpretation of the results must be very cautious. The increase in OR and $\mathrm{HR}$ shown in previous studies was small, but the $P$-value was significant. This is because the number of subjects included in population-based studies is very large, so that even slight differences are meaningful. It is therefore unlikely that these results will be identical to those experienced by researchers in actual clinical practice. In addition, the present investigation was conducted using electronic health records, rather than being authentic epidemiologic research, so the results should not be interpreted as necessarily indicating a causal relationship.

Although not evaluated in the present study, another important factor in the relationship between AMI and GERD is that of the drugs used to treat GERD. Since most patients diagnosed

Received: August 24, 2020 Revised: None Accepted: August 29, 2020

@) This is an Open Access article distributed under the terms of the Creative Commons Attribution Non-Commercial License (http://creativecommons. org/licenses/by-nc/4.0) which permits unrestricted non-commercial use, distribution, and reproduction in any medium, provided the original work is properly cited.

*Correspondence: Su Young Kim, MD, PhD

Division of Gastroenterology, Department of Internal Medicine, Yonsei University Wonju College of Medicine, 20 Ilsan-ro, Wonju, Gangwon-do 26426, Korea

Tel: +82-33-741-0507, Fax: +82-33-747-3538, E-mail: breeze1212@yonsei.ac.kr 
with GERD use acid-suppressing drugs, the potential association between these drugs and AMI cannot be ignored. One such treatment that has been the subject of previous research is the proton pump inhibitor (PPI). Shah et $\mathrm{al}^{7}$ showed that GERD patients exposed to PPIs had a 1.16-fold increase in myocardial infarction. However, other studies have reported no definite association between PPIs and AMI., ${ }^{4,8}$ In fact, one study found that GERD patients who were prescribed PPIs had a slightly decreased risk of AMI compared to those not taking PPIs ( $\mathrm{HR}=0.57 ; 95 \% \mathrm{CI}$, $0.31-1.04 ; P=0.066){ }^{5}$ A recent large cohort study found no evidence that prescription PPIs raised the risk of AMI compared with prescription histamine-2 receptor antagonists. ${ }^{8}$ Taking these studies together, PPIs do not appear to have any definite effect on AMI.

In this study, the authors found higher incidence of AMI in patients with GERD than in those without GERD, but stated that this difference was not likely to be clinically meaningful. In addition, hypertension, hyperlipidemia, and diabetes, which are well-known risk factors for AMI, have shown that the OR value increases as a risk factor for AMI. Considering that there are few studies on the association between AMI and GERD, this study has originality. However, since sensitivity analysis and validation of the study subjects were not sufficiently performed, there are limitations in interpreting the results. In summary, to date, the association between GERD and AMI remains undetermined. Some studies have shown probable results for the association, but have failed to show any definitive clinically meaningful conclusions. In the future, a well-controlled and well-planned study design is required to draw conclusions about this association. There is no need to worry about GERD as a risk factor for AMI until a definite conclusion is reached.

\section{Financial support: None.}

\section{Conflicts of interest: None.}

\section{References}

1. Mahmood SS, Levy D, Vasan RS, Wang TJ. The Framingham Heart Study and the epidemiology of cardiovascular disease: a historical perspective. Lancet 2014;383:999-1008.

2. Smith KS, Papp C. Episodic, postural, and linked angina. Br Med J 1962;2:1425-1430.

3. Chauhan A, Petch MC, Schofield PM. Effect of oesophageal acid instillation on coronary blood flow. Lancet 1993;341:1309-1310.

4. Johansson S, Wallander MA, Ruigómez A, García Rodríguez LA. Is there any association between myocardial infarction, gastro-oesophageal reflux disease and acid-suppressing drugs? Aliment Pharmacol Ther 2003;18:973-978.

5. Lei WY, Wang JH, Wen SH, et al. Risk of acute myocardial infarction in patients with gastroesophageal reflux disease: A nationwide populationbased study. PLoS One 2017;12:e0173899.

6. Eisa M, Sandhu A, Prakash R, Ganocy SJ, Fass R. The risk of acute myocardial infarction in patients with gastroesophageal reflux disease. J Neurogastroenterol Motil 2020;26:471-476.

7. Shah NH, LePendu P, Bauer-Mehren A, et al. Proton pump inhibitor usage and the risk of myocardial infarction in the general population. PLoS One 2015;10:e0124653.

8. Landi SN, Sandler RS, Pate V, Lund JL. No increase in risk of acute myocardial infarction in privately insured adults prescribed proton pump inhibitors vs histamine-2 receptor antagonists (2002-2014). Gastroenterology 2018;154:861-873, e6. 